Abstract

\title{
Improving Space Based Snowfall Rate Retrievals with Refined Considerations of Snow Microstructure ${ }^{\dagger}$
}

\author{
Farrukh Chishtie ${ }^{1, *}$, David Hudak ${ }^{2}$ and Peter Rodriguez ${ }^{2}$ \\ 1 Asian Disaster Preparedness Center, SERVIR-Mekong, Bangkok 10400, Thailand \\ 2 Cloud Physics and Extreme Weather Research, Environment and Climate Change Canada, King City, \\ ON M3H 5T4, Canada; david.hudak@canada.ca (D.H.); peter.rodriguez@canada.ca (P.R.) \\ * Correspondence: farrukh.chishtie@adpc.net \\ + Presented at Symmetry 2017-The First International Conference on Symmetry, Barcelona, Spain, \\ 16-18 October 2017.
}

Published: 5 January 2018

Launched in 2014 as a joint mission by the Japanese Aerospace Exploration Agency (JAXA) and the National Aeronautics and Space Administration (NASA), a key goal of the Global Precipitation Mission (GPM) is to quantify when, where, and how much it rains or snows around the world. In contrast to rainfall measurements, whereby scattering theory works considerably better with the assumption of spherically symmetric hydrometeors, snowfall retrievals are complicated by the microstructure of the snowflakes. Though symmetric in many cases, snowflakes also possess complex shapes which makes microwave scattering and related snowfall rate retrievals relatively less accurate. In this poster presentation, the present GPM retrieval algorithm is presented which is contrasted with ground measurements conducted in the OLYMPEX ground validation experiment over the Olympic Mountains in the US in the winter of 2015-2016. This experiment is presented in detail and preliminary results show less than desirable accuracy when comparing GPM measurements with measured reflectivity on the ground. Given these considerations, this poster provides an overview of present approaches to improve these retrievals which include special and generalized considerations of the Rayleigh-Gans approximation. It is surmised that better considerations of snow microstructure have the potential of improving snowfall retrieval from space based sensors such as the GPM.

(C) 2018 by the authors. Licensee MDPI, Basel, Switzerland. This article is an open access article distributed under the terms and conditions of the Creative Commons Attribution (CC BY) license (http://creativecommons.org/licenses/by/4.0/). 